http://www.jfas.info

\title{
EFFECT OF SUBSTRATE PRE-SOLDERING TEMPERATURE ON WETTABILITY OF SAC387 LEAD-FREE SOLDER
}

\author{
N. N. M. Fedzir ${ }^{1, *}$, W. Y. W. Yusoff ${ }^{1}$ and A. Jalar ${ }^{2}$ \\ ${ }^{1}$ Center of Foundation Studies, Universiti Pertahanan Nasional Malaysia, Sungai Besi, 57000 \\ Kuala Lumpur, Malaysia \\ ${ }^{2}$ Faculty of Applied Science, Universiti Kebangsaan Malaysia, 43600 Bangi, Selangor, \\ Malaysia
}

Published online: 10 September 2017

\begin{abstract}
This study highlights the solderability of Sn-Ag-Cu (SAC387) on a copper substrate with different pre-soldering temperature. The contact angle measured for the wettability of SAC 387 lead-free solder indicates the solderability and soldering condition. Hand soldering of solder onto copper substrate with three different pre-soldering temperature of $60^{\circ} \mathrm{C}, 80^{\circ} \mathrm{C}$ and $100^{\circ} \mathrm{C}$. Then, the solder sample was cross-sectioned and viewed under an optical microscope to study the contact angle. The result shows the wettability of SAC 387 lead-free solder sample at $100^{\circ} \mathrm{C}$ has the lowest contact angle compared to samples prepared at $60^{\circ} \mathrm{C}$ and $80^{\circ} \mathrm{C}$. Consequently, the lower in contact angle led to the increasing in wettability of SAC 387 lead-free on a copper substrate.
\end{abstract}

Keywords: wettability; lead-free solder; SAC 387; $\mathrm{Sn}-\mathrm{Ag}-\mathrm{Cu}$; copper substrate; contact angle.

Author Correspondence, e-mail: nurulnabilahfedzir@gmail.com doi: http://dx.doi.org/10.4314/jfas.v9i3s.13 


\section{INTRODUCTION}

One of the crucial factors to check on the efficiency of manufacturing and the reliability of an electronic packaging is the wettability [15]. Wettability can be defined as the tendency for a liquid to spread on the solid substrate [13]. The soldering process is important to ensure a good metallurgical bond between the solder joint in the microelectronics especially in printed circuit boards (PCB). Previous studies have indicated that the temperature of the substrate and the solder materials are the most significant factors that affect the wettability of solder joint. The ability of the solder to wet on the microelectronic package also is one of the factors in determining the performance of the product. In this study, Sn-Ag-Cu (SAC387) lead-free solder has been selected to use as the solder material. Lead-free solder alloy is chosen due to its properties which are harmless to the human and environment. Even though lead has proved a good wettability in solder but it is characterized as harmful toxic to the human that caused by the lead poisoning, even dead. This alternative replacement on using lead-free is the example of environmental concern in semiconductor industry.

The effect of wettability on the reliability of solder joint may depend not only on the temperature but also on material, surface roughness of the substrate. The objectives of this study were to investigate the effect of substrate pre-soldering temperature on the wettability of solder joints. Besides that, for melted solder, the efficiency of wetting depends on two major factor which is wettability level and wettability speed. The wettability level can be concluded as the level of spreading or condition of melted solder on the surface substrate. The wettability speed is the spreading's speed of the melted solder on the substrate. Besides that, wettability speed is also known as wetting time or spreading rates which reflect the relative performance that generally measure for quantitative values of the sample [2]. These two major factors can be examined by using pre-soldering temperature of the substrate as the parameters to confirm the wettability behavior.

In a process of soldering, good wettability between solders and substrate is required to ensure good microelectronic packaging applications [9]. In [6] shows a good wettability is determined by the degree of solder contact of the solder joint. The pre-soldering temperature on the substrate is perhaps the key factors that influence the wetting properties of solder joints. 
The wetting properties of solder are greatly influenced by soldering temperature [4]. Commonly observed, a soldering process in different temperature tend to create a different result on wetting condition of the solder joint between solder and substrate. The purpose of current work is to demonstrate the effect of substrate pre-soldering temperature on the contact angle and wetting time of SAC387 lead-free solders with the copper substrate. The contact angle and wetting time determined is measured the wettability of solder whether it is a good or poor wettability performance of the solder joint. Wettability of solder was also performed for comparison within these three different temperatures as the parameters. The wetting behavior of SAC 387 lead-free solder on a copper substrate was examined. The experiments included contact angle measurement of three SAC 387 lead-free solders on three different pre-soldering temperature. According to Fig. 1, the contact angle can be determined by using Infinite Focus Microscope (IFM). The easiest way to examine a wetting process is by the measure of wetting angle [12]. The measurement of contact angles as the main data is the studies of wettability, which indicates the degree of wetting when a solid and liquid interact [3].
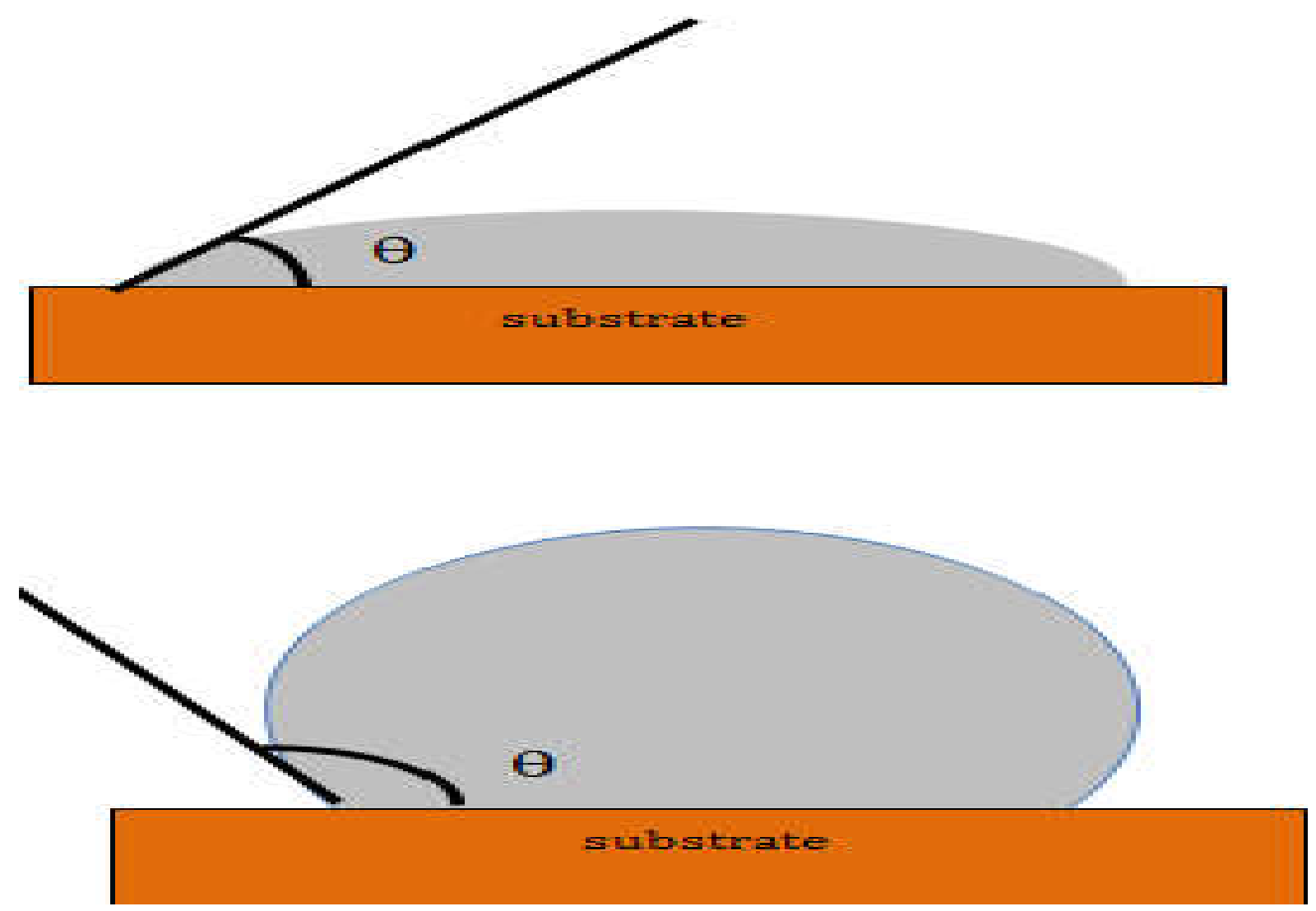

Fig.1. Illustration of contact angles formed by liquid drops on a solid surface 
The melted solder formed on the substrate are spherical in shape. This shape represents the minimum surface area for a fixed volume. The unbalanced forces in the molecules at the surface of melted solder will cause a surface tension as in Fig. 2. The surface tension is important in order to determine the shape of the solder thus the wettability of the solder joint. The contact angle was formed by the combination of surface tension and gravity force (external force). It is indicated where the melted solder ends and the surface begins. The contact angles can be calculated using Young's equation to obtain the measurements [7].

$\gamma \mathrm{l} v * \cos \theta \mathrm{Y}=\gamma \mathrm{sv}-\gamma \mathrm{sl}$

where $\gamma \mathrm{l} v, \gamma \mathrm{s} v$ and $\gamma \mathrm{sl}$ represent the liquid-vapor, solid-vapor and solid-liquid interfacial tensions respectively and $\theta Y$ is the contact angle. Equation (1) is usually referred to as Young's equation and $\theta Y$ is Young's contact angle.

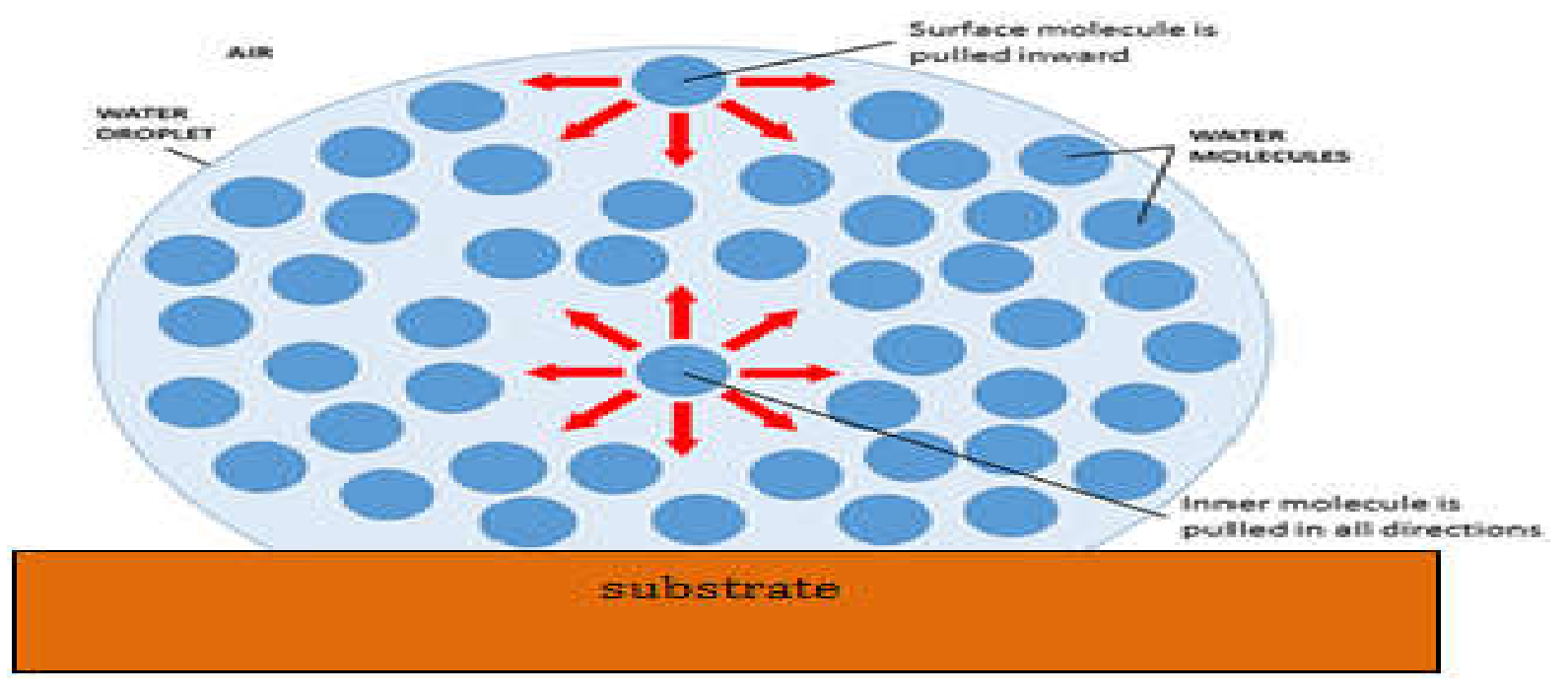

Fig.2. Illustration of surface tension in water molecule

This Young's equation revealed the relation between contact angle and interfacial tension. The value of Young's contact angle, $\theta$ Y will directly show us the wettability between solder alloy and the substrate. It also shows when the contact angle value was small, the solder was generally has a good wetting ability or meaning that the solder spreads out more on the substrate. Fig. 3 shows a wetting condition for a solder melted on a solid substrate. A complete wetting condition has a contact angle $\left(\theta=0^{\circ}\right)$, while a complete non-wetting condition has $\left(\theta=180^{\circ}\right)[10]$. 


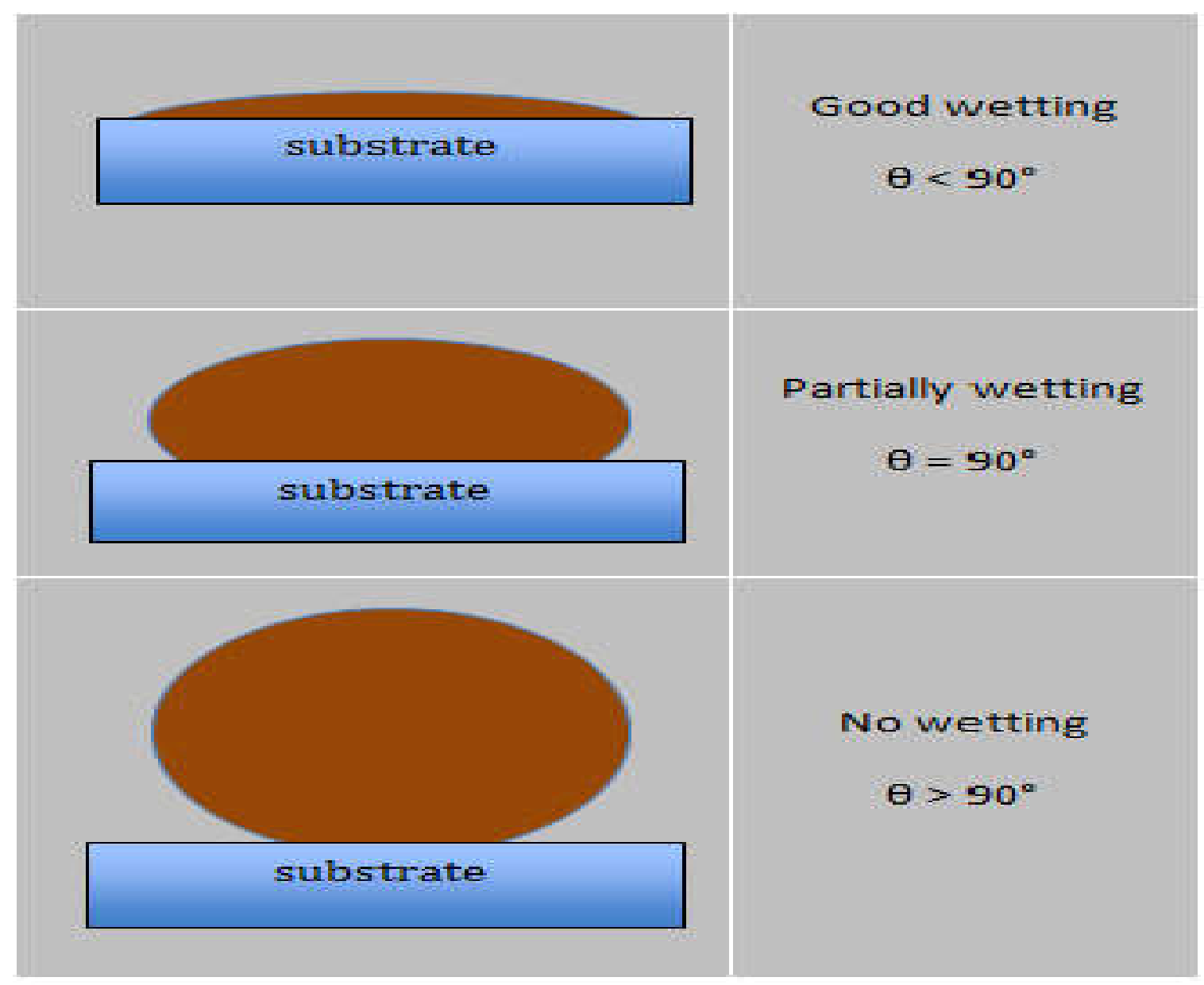

Fig.3. Illustration of contact angles formed by liquid drops on a solid surface

The aim of this study is to understand the wetting behavior of the Sn-95.5Ag-3.8Cu-0.7 (SAC387) lead-free solder alloy by measuring the contact angle on different substrate pre-soldering temperature using Infinite Focus Measurement (IFM) system. In addition, the main data of the study is based on wettability level and wettability speed obtained. By using this method, the measurement of the contact angle (wetting angle) and the formation of wetting properties will be also examined.

\section{EXPERIMENTAL}

The lead-free solder wire, Sn-95.5Ag-3.8Cu-0.7 (SAC387) with a diameter size of $0.6 \mathrm{~mm}$ and a $\mathrm{Cu}$ plate as a substrate with dimensions $2 \mathrm{~cm} \times 1 \mathrm{~cm} \times 0.3 \mathrm{~cm}$ had been used in the study. The solder wire used for the wetting experiment was supplied by Redring Solder (M) Sdn. Bhd. Before soldering process, the copper plates were cleaned with acetone in an ultrasonic bath for $5 \mathrm{~min}$ to remove oxide layer and small particles from the surface. The 
oxide layer can affect the surface of the copper plate that can cause a non-wetting conditions. Moreover, the spreading of the solder to wet the surface of the substrate will also effect. The copper plates were dried and ready for soldering. In this study, the objective was to determine the contact angle of the solder as the temperature is the parameters, so it was soldered on the electronic hot plate as in Fig. 4.

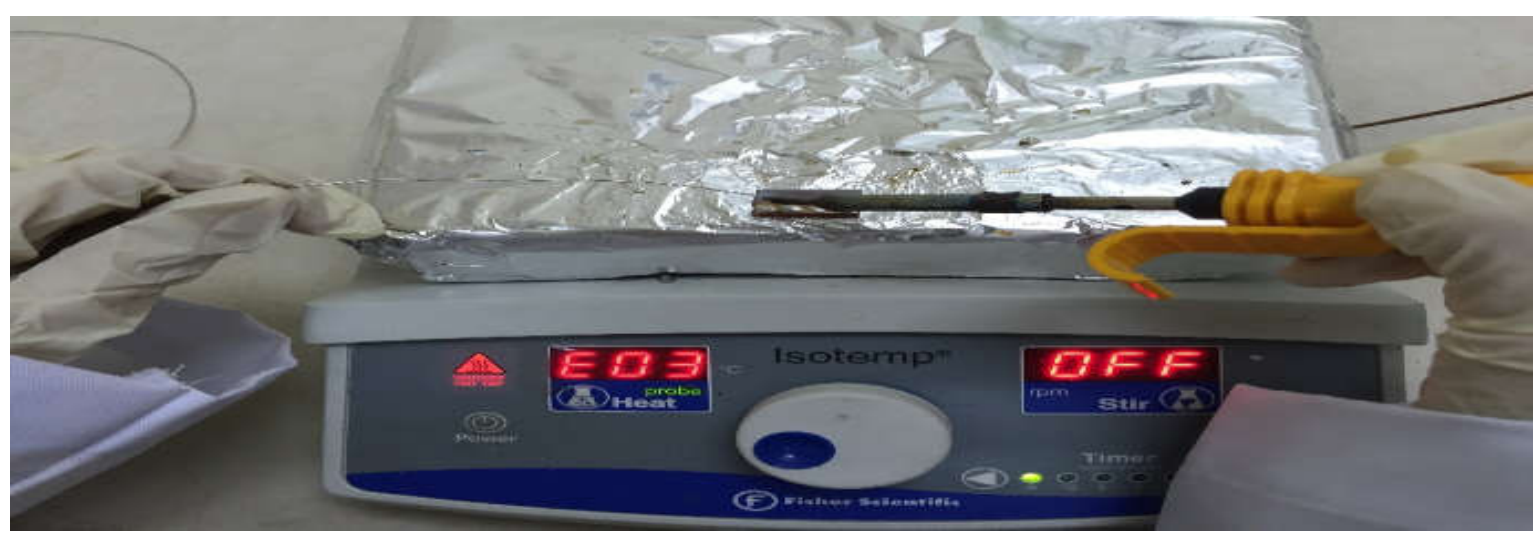

Fig.4. Hand soldering process

The soldering process undergoes at three different pre-soldering temperatures which are $60^{\circ} \mathrm{C}$, $80^{\circ} \mathrm{C}$ and $100^{\circ} \mathrm{C}$ respectively. The copper plates were placed on the electronic hot plate once it achieved the objective temperature. To begin with, the solder alloy was soldered on a substrate at $60^{\circ} \mathrm{C}$ first due to increasing in temperature of the electronic hot plate. Then, the soldering process followed by $80^{\circ} \mathrm{C}$ and $100^{\circ} \mathrm{C}$. The time taken for the soldered sample melted is also recorded to determine the wettability speed of each three different pre-soldering temperature soldered sample (Fig. 5). The time taken was measured during the temperature achieved until the solder alloy melted on the copper plate (substrate). Then, all the soldered sample were allowed to cool down to room temperature before subjected to a standard metallographic technique such as mounting, grinding and polishing.

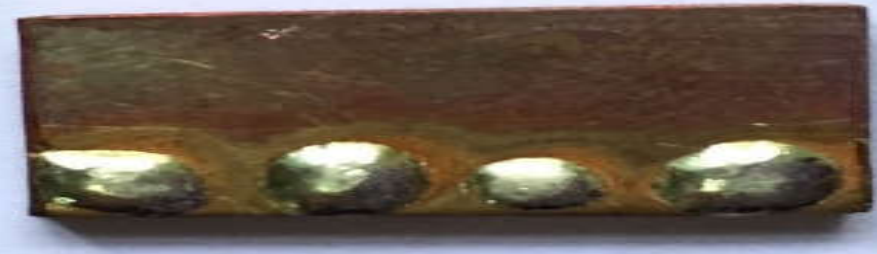

Fig.5. Soldered sample 
The metallographic technique was used to obtain the cross sectional of the sample. This step is used to examine whether the solder melted spreading on the substrate thus confirmed the wetting condition of the sample on different pre-soldering temperature. Furthermore, metallographic technique started by mounting the sample using cold mounting resin then followed by the wet grinding with 600,800 and 1200 grit abrasive paper. Lastly, the sample was polished with $1 \mu \mathrm{m}$ diamond suspensions on silk cloths. The polished sample as in Fig.6 was viewed under Infinite Focus Measurement (IFM) system.

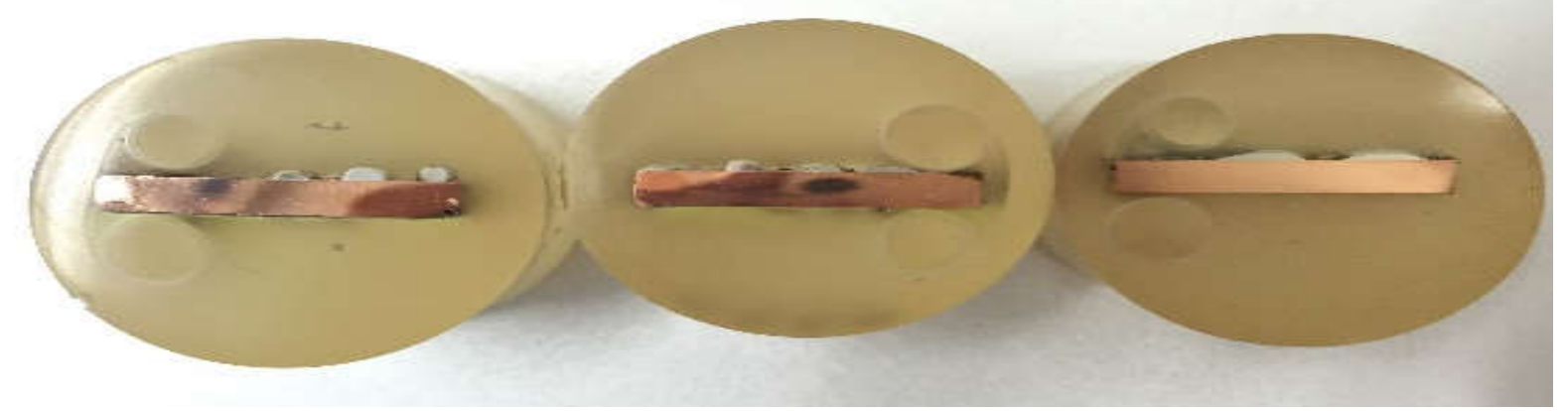

Fig.6. Cross section of the sample after mounting, grinding and polishing

Contact angle measurement can be determined by using several methods. The previous study was shown, the simplest ways to find the contact angle between a solder melted and solid substrate is by using Infinite Focus Measurement (IFM) system as in Fig. 6. This instrument capable of scanning with a resolution of up to $5 \mathrm{x}$ magnification. The contact angle measurements were made on the 2D image captured. Finally, the value of contact angle shows the wetting angle between solder melted and the copper substrate. The wetting angle for each three different pre-soldering temperature was analyzed and the wetting behavior were determined.

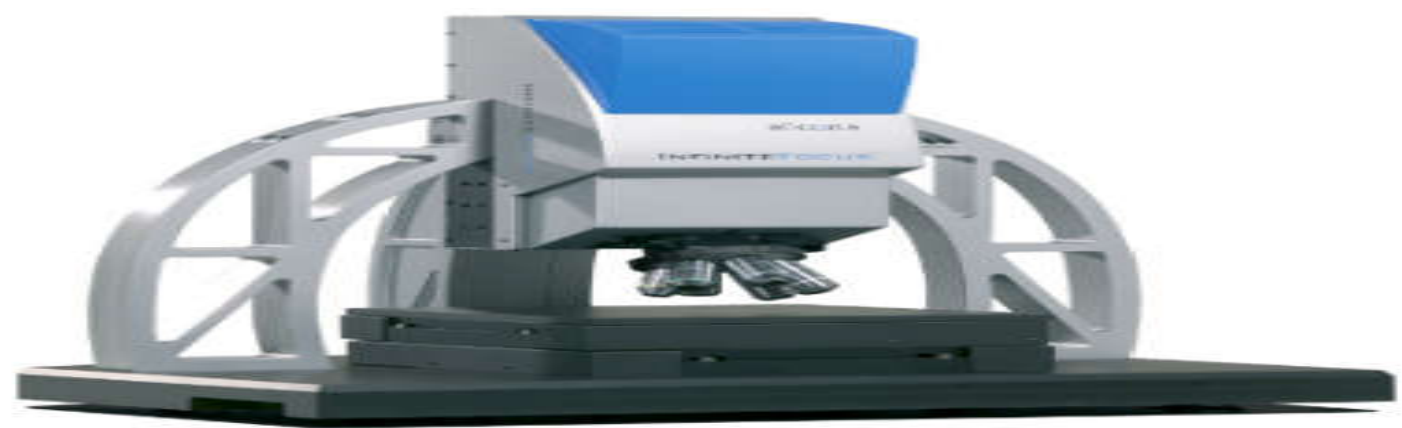

Fig.7. Infinite focus measurement (IFM) 


\section{RESULTS AND DISCUSSION}

Fig. 8-10 show the qualitative results on of contact angle, $\theta$ for SAC 387 lead-free solder alloy at $60^{\circ} \mathrm{C}, 80^{\circ} \mathrm{C}$ and $100^{\circ} \mathrm{C}$. All the images in figures indicate the clear formation of solder joint at different substrate pre-soldering temperature. The formation of the solder joint strongly depends on the condition of the solder wetted on $\mathrm{Cu}$ substrate.

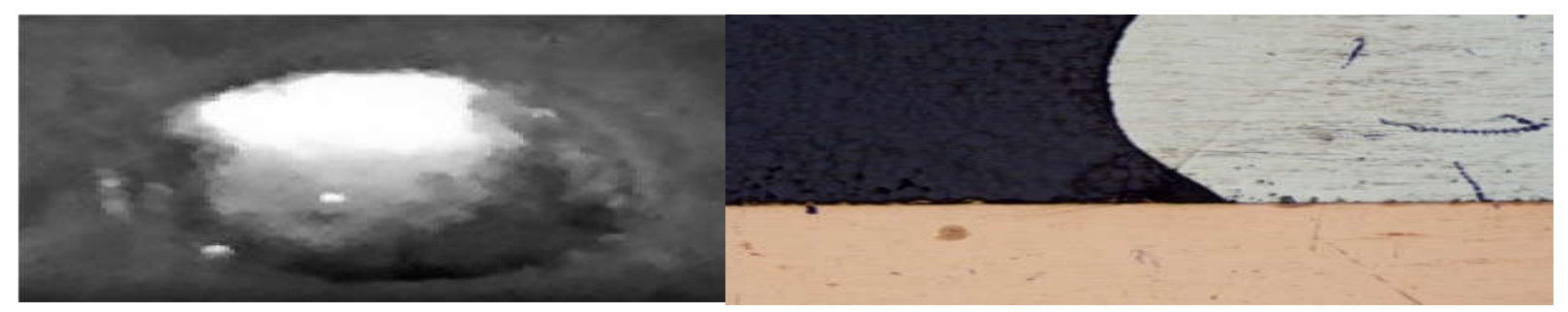

(a)

(b)

Fig.8. Solder joint of $\mathrm{Sn} 95.5 \mathrm{Ag} 3.8 \mathrm{Cu} 0.7(\mathrm{SAC} 387)$ at $60^{\circ} \mathrm{C}$

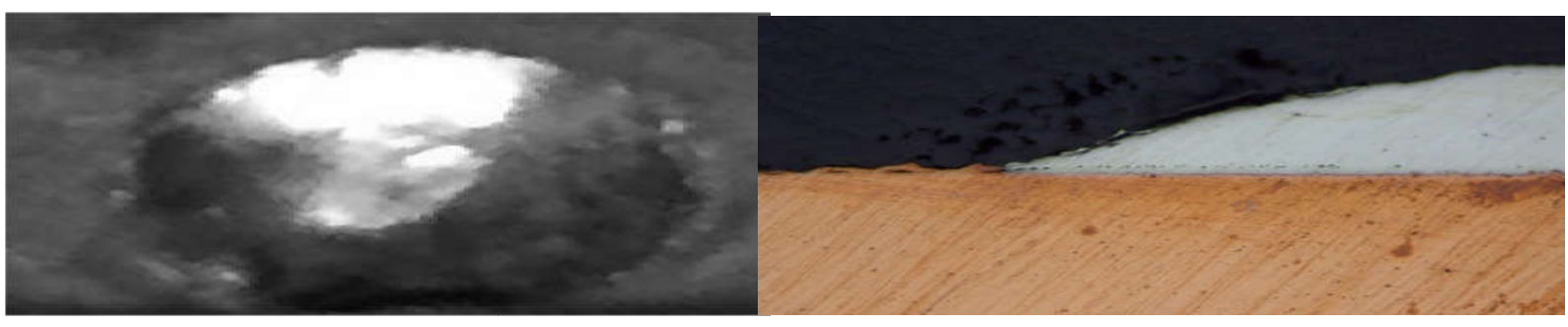

(a)

(b)

Fig.9. Solder joint $\mathrm{Sn} 95.5 \mathrm{Ag} 3.8 \mathrm{Cu} 0.7(\mathrm{SAC} 387)$ at $80^{\circ} \mathrm{C}$

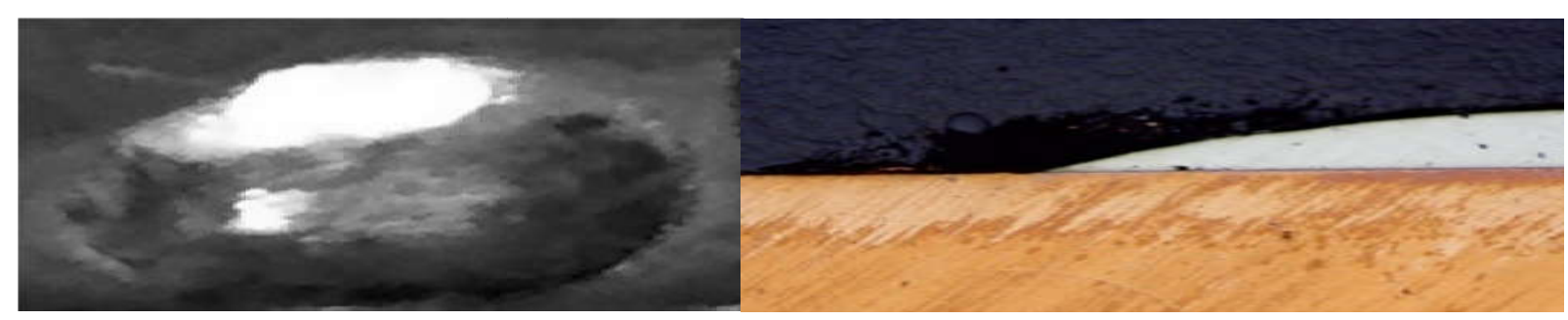

(a)

(b)

Fig.10. Solder joint of Sn95.5Ag3.8Cu0.7 (SAC387) at $100^{\circ} \mathrm{C}$

In addition, the formation was characterized to identify a good wetting shape of the solder joint. It was observed that the formation of solder joint spread and wetted on copper substrate poorly at $60^{\circ} \mathrm{C}$, but with the increasing of temperature to $80^{\circ} \mathrm{C}$ and $100^{\circ} \mathrm{C}$ their wetting behavior improves noticeably. This indicates that the pre-soldering temperature will affect the wetting behavior.

Further analysis has been carried out and the value of contact angle at different pre-soldering 
temperature is shown in Table 1. The quantitative result of contact angle, $\theta$ for SAC 387 lead-free solder alloy at $60^{\circ} \mathrm{C}, 80^{\circ} \mathrm{C}$ and $100^{\circ} \mathrm{C}$. For the sample soldered on the substrate pre-soldering temperature of $60^{\circ} \mathrm{C}$, contact angles value obtained was about $\left(\theta=133^{\circ}\right)$ while $\left(\theta=26^{\circ}\right)$ and $\left(\theta=12^{\circ}\right)$ for the temperature of $80^{\circ} \mathrm{C}$ and $100^{\circ} \mathrm{C}$ respectively. Moreover, the contact angle values decreased with the increasing of temperature. The smallest contact angle obtained is at the temperature of $100^{\circ} \mathrm{C}$, while the highest contact angle obtained is at a temperature of $60^{\circ} \mathrm{C}$. Classification of good wetting based on the contact angle between solder joint. Thus, at temperature $100^{\circ} \mathrm{C}$, the wettability is better than at the temperature of $60^{\circ} \mathrm{C}$ and $80^{\circ} \mathrm{C}$ due to its smallest value obtained for the contact angle.

Table 1. Lead free solder (SAC387) contact and wetting condition

\begin{tabular}{ccc}
\hline Pre-Soldering Temperature, $\left({ }^{\circ} \mathbf{C}\right)$ & Contact Angle, $\boldsymbol{\theta}\left({ }^{\circ}\right)$ & Wetting Condition \\
\hline 60 & 133 & Non wetting \\
80 & 26 & Wetting \\
100 & 12 & Completely wetting \\
\hline
\end{tabular}

Besides that, the graph of contact angle for SAC387 lead-free solder alloy versus pre-soldering temperature subjected during the soldering process has plotted in Fig. 11. From the graph, it is clear that pre-soldering temperature has affected the contact angle obtained for SAC 387 lead-free solder. Likewise, the trend of the graph shows that in low temperature, solder tend to has a greater contact angle due to the ability of solder wire to melt on the copper substrate.

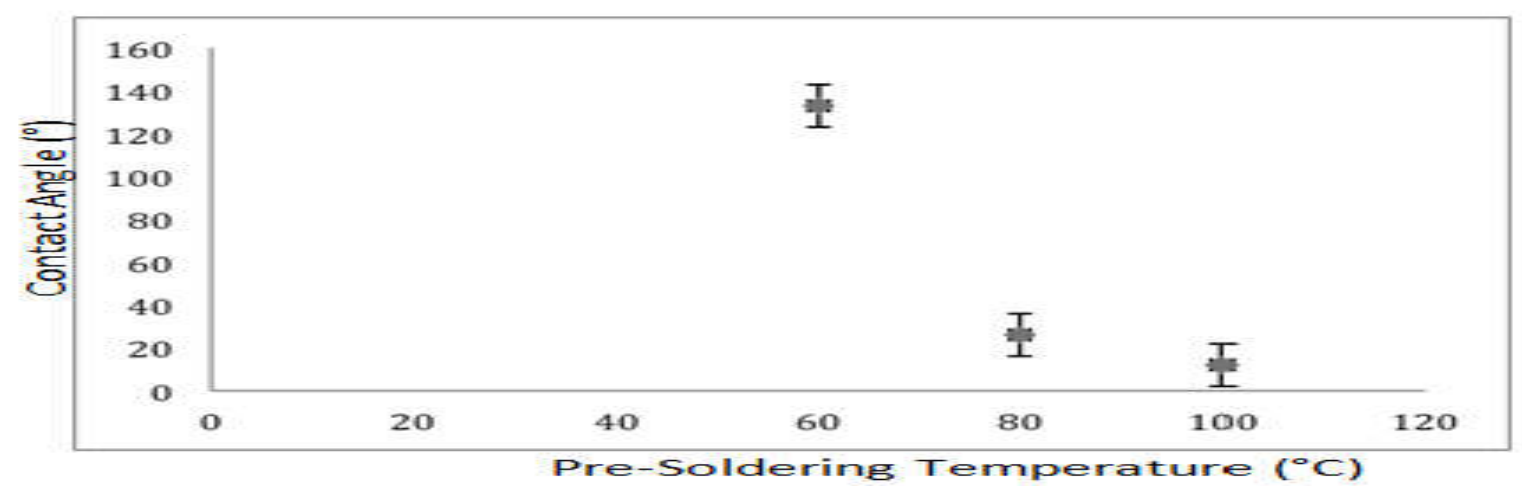

Fig.11. Contact angle of SAC387 lead-free alloy versus pre-soldering temperature

The wettability of solder joint can be determined from the degree of contact angle obtained [14]. In addition, small contact angle value between the substrate surface and the solder alloy 
gives perfect wetting. In [16] shows that the contact angle less than $90^{\circ}\left(\theta<90^{\circ}\right)$, the degree of spreading of a solder alloy is higher on the substrate thus the wettability becomes better. On the other hand, if the contact angle obtained larger $\left(\theta>90^{\circ}\right)$, it is considered as non-wetting on the substrate that gives poor wettability. Furthermore, when both materials which are molten solder and solid (substrate) come in contact together, there are an interaction and repulsion forces between the materials which are intermolecular forces [15].

This force is responsible for contracting the surface between the lead-free solder and copper substrate. Moreover, this intermolecular forces can be described by cohesion and adhesion forces. At higher temperature the attraction (cohesion forces) is weaker, thus intermolecular cohesion forces approach zero and surface tension becomes very small [11]. The smaller the contact angle, the cohesive forces are weaker than adhesive forces thus the liquid tend to interact more and tend to spreads easily on the substrate. From the adhesion forces will determine the contact angle created between liquid and solid interface. In [1] shows the adhesion force is important to ensure the solder wet the surface of the copper substrate. If the contact angle is greater than $90^{\circ}$, then the liquid does not spread on the solid and no adhesion occurs, thus, it has a poor wettability.

Furthermore, the wettability of solder joint is also determined by the wetting time during the soldering process. Wetting time is one of the factors that contributes to a good wettability. The results in Table 2 shows the wetting time obtained for the three soldered sample on different pre-soldering temperature. At $60^{\circ} \mathrm{C}$, the wetting times obtained is the highest while the value found is smallest at $100^{\circ} \mathrm{C}$. In studying the pre-soldering temperature effect, the wetting time of all sample soldered decreases with the increasing temperature. This phenomenon is the result of metallurgical reactions, fluidity and surface tension occur during the soldering process [8].

Table 2. Lead free solder (SAC387) wetting time and wetting condition

\begin{tabular}{ccc}
\hline Pre-Soldering Temperature, $\left({ }^{\circ} \mathbf{C}\right)$ & Contact Angle, $\boldsymbol{\theta}\left({ }^{\circ}\right)$ & Wetting Condition \\
\hline 60 & 11.0 & Non wetting \\
80 & 7.0 & Wetting \\
100 & 4.0 & Completely wetting \\
\hline
\end{tabular}


In addition, the graph of wetting time for SAC387 lead-free solder alloy versus pre-soldering temperature has plotted in Fig. 12. It depicted that at a temperature of $100^{\circ} \mathrm{C}$, the wetting time is smaller compared to at $60^{\circ} \mathrm{C}$ and $80^{\circ} \mathrm{C}$. Fig. 12 summarize the wetting ability of SAC 387 lead-free solder increases as the pre-soldering temperature increase. It should be noted that SAC387 lead-free solder alloy had much longer wetting time and did not meet the good wettability criteria. This shows that wetting properties is influenced by pre-soldering temperature.

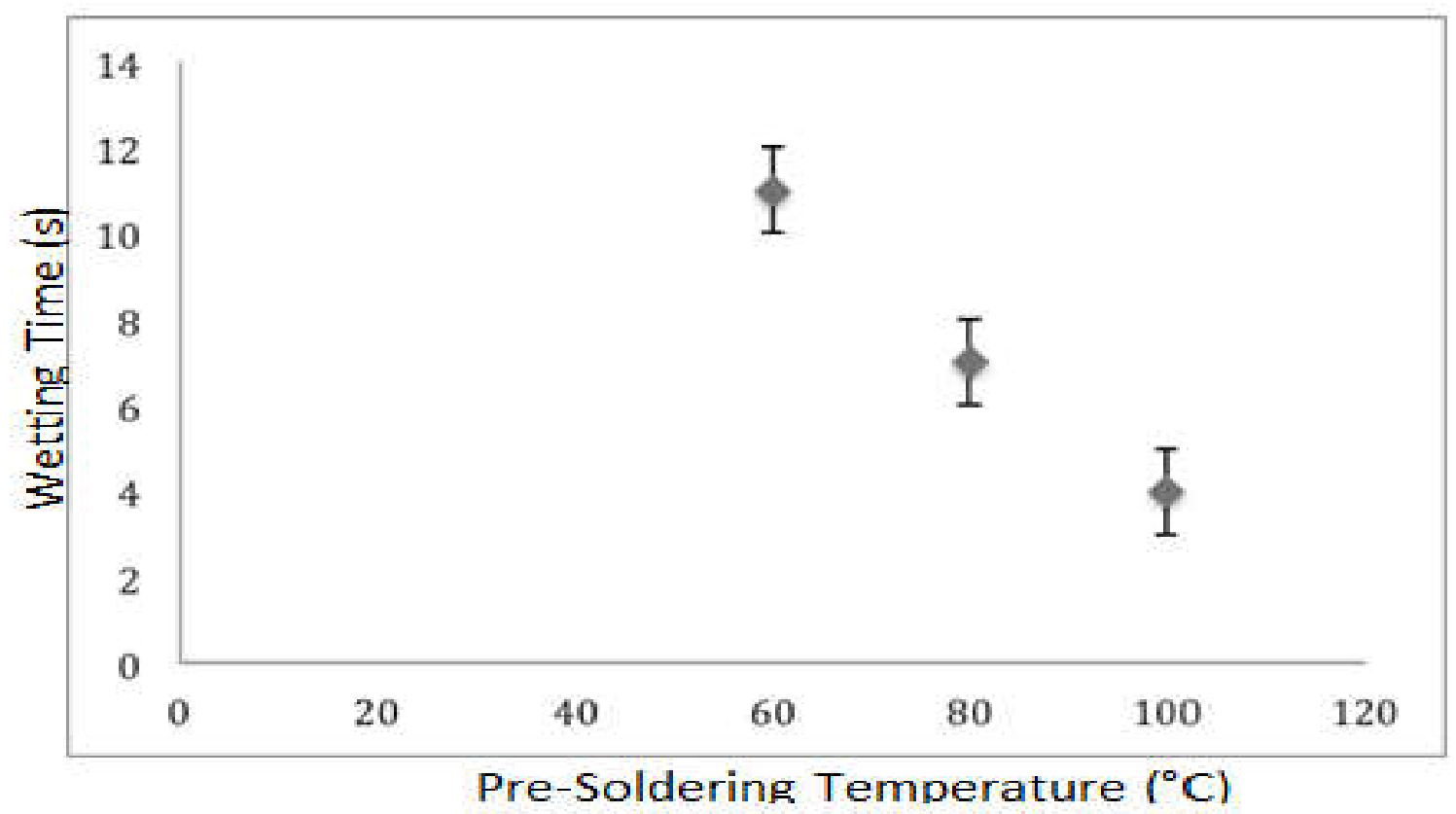

Fig.12. Wetting time of SAC387 lead-free alloy versus pre-soldering temperature In [14] shows the soldering process at high temperature has a positive impact on wettability. Contact angle values of SAC 387 solder decreased with increasing soldering temperatures. Conversely, SAC 387 solder has higher contact angle values when soldered at low temperatures. Moreover, for the wettability speed, the wetting times decreases as the pre-soldering temperature increase. Therefore, the wetting ability of SAC 387 lead-free solder increases as the pre-soldering temperature increase. Hence, these indicate the wettability will be upgraded if the temperature was higher and the contact angle was higher, implying that at $100^{\circ} \mathrm{C}$ the solder has better wettability.

\section{CONCLUSION}

In this study, the effect of pre-soldering temperature to wettability of Sn-95.5Ag-3.8Cu-0.7 
(SAC387) lead-free solder alloy was investigated by measuring their contact angle on the copper substrate. The two major factor in studying wettability properties, which are wettability level and wettability speed was the main data during the wetting test. It was measured by qualitatively and quantitatively. Qualitatively at $100^{\circ} \mathrm{C}$, the formation of solder joint was observed to spread and wet better on the copper substrate compared to that of at $60^{\circ} \mathrm{C}$ and $80^{\circ} \mathrm{C}$. Likewise, quantitatively at $100^{\circ} \mathrm{C}$, the contact angle and wetting times were smallest $\left(\theta=12^{\circ}\right)$ and $\mathrm{t}=4 \mathrm{~s}$ among others sample. It was demonstrated that the contact angle and wetting times between Sn-95.5Ag-3.8Cu-0.7 (SAC387) lead-free solder alloy with copper substrate become smaller with the increasing temperature, thus better the wettability. It clearly indicates that higher temperature resulted in improvement of wettability of Sn-95.5Ag-3.8Cu-0.7 (SAC387) lead-free solder alloy.

\section{ACKNOWLEDGEMENTS}

The authors gratefully acknowledge the financial support from Ministry of Higher Education (MoHE) Malaysia under the Fundamental Research Grant Scheme (FRGS) R0069-FRGS/1/2015/SG06/UPNM/03/1 and National Defence University of Malaysia (NDUM).

\section{REFERENCES}

[1] Abhyankar H. Mechanisms of thermoplastics to metal adhesion for applications in electronics manufacture. PhD thesis, Leicestershire: Loughborough University, 2011

[2] Blake T D, Fernandez-Toledano J C, Doyen G, De Coninck J. Forced wetting and hydrodynamic assist. Physics of Fluids, 2015, 27(11):112-120

[3] Extrand C W. Uncertainty in contact angle estimates from a Wilhelmy tensiometer. Journal of Adhesion Science and Technology, 2015, 29(23):2515-2520.

[4] Feng X L, Yang J. Effect of Pr on wettability and mechanical property of Sn- $0.3 \mathrm{Ag}-0.7 \mathrm{Cu}$ lead-free solder. AMR Advanced Materials Research, 2015, 1120:456-461

[5] Fowkes F. M., Adamson A. W. Hydrophobic surfaces. New York: Academic Press, 1969

[6] Hu A J, Lv B Z, Wang X S, Zhou L. The contact angle for a droplet on homogeneous and 
spherical concave surfaces. Modern Physics Letters B, 2016, 30(7):65-78

[7] Hwang J S, Kho V, Chew H K. The role of wetting ability of lead-free alloys. International Journal of Microcircuits and Electronic Packaging, 2001, 24(4):272-281

[8] Kumar G, Prabhu K N. Review of non-reactive and reactive wetting of liquids on surfaces. Advances in Colloid and Interface Science, 2007, 133(2):61-89

[9] Mhd Noor E E, Mhd Nasir N F, Idris S R A. A review: Lead free solder and its wettability properties. Soldering and Surface Mount Technology, 2016, 28(3):125-132

[10] Patra S. Surface tension in pharmaceutical dosage forms. Journal of Life Science and Biotechnology, 2016, 1:17-19

[11] Rodrigues N, Ferreira A C, Teixeira S F, Soares D, Teixeira J C, Cerqueira F, Macedo F. Contact angle measurement of SAC 305 solder: Numerical and experimental approach. Journal of Materials Science: Materials in Electronics, 2016, 27(9):8941-8950

[12] Silva B L, Cheung N, Garcia A, Spinelli J E. Evaluation of solder/substrate thermal conductance and wetting angle of $\mathrm{Sn}-0.7 \mathrm{wt} \% \mathrm{Cu}-(0-0.1 \mathrm{wt} \% \mathrm{Ni})$ solder alloys. Materials Letters, 2015, 142:163-167

[13] Takyi G, Bernasko P K. Investigation of wettability of lead free-solder on bare copper and organic solder preservatives surface finishes. International Journal of Materials Science and Applications, 2015, 4(3):165-172

[14] Terpiłowski K. Influence of the ambient temperature on water and diiodomethane contact angle with quartz surface. Annales UMCS, Chemia, 2015, 70(1):1-10

[15] Yoon S W, Choi W K, Lee H M. Calculation of surface tension and wetting properties of Sn-based solder alloys. Scripta Materialia, 1999, 40(3):297-302

[16] Yuan Y, Lee T R. Contact angle and wetting properties. In G. Bracco, B. Holst (Eds.), Surface science techniques: Springer series in surface sciences. Berlin: Springer, 2013, pp. 3-34.

\section{How to cite this article:}

Fedzir NNM, Yusoff WYW, Jalar A.Effect of substrate pre-soldering temperature on wettability of sac387 lead-free solder. J. Fundam. Appl. Sci., 2017, 9(3S), 154-166. 